\title{
An intentional profit-generating strategy can be detrimental to a sustainable organisation
}

\section{Jayani Chakravarti ${ }^{a}$ and Frédéric Basso ${ }^{b^{*}}$}

The Behaviouralist, 5 Hoxton Square, London, N1 6NU, UK

Department of Psychological and Behavioural Science, London School of Economics and Political Science, Houghton Street, London WC2A 2AE, UK.

*Corresponding author. Email: f.basso@1se.ac.uk

\begin{abstract}
Sustainable organisations have to be profitable to maintain their economic and social activity. However, prior literature finds that people are reluctant to associate profitability with sustainability, which leads to negative judgement. Through experimental evidence, the current research supports this idea but shows that profitability actually backfires within sustainable organisational contexts when it is intentional, rather than unintentional. Results indicate that consumers use a zero-sum heuristic on resource allocation when they are presented with a green product that is intentionally (vs. unintentionally) profit-generating. They infer from intended (vs. unintended) profitability that the organisation devoted greater resources to make profit rather than to make the product more sustainable. This product thus appears less sustainable to consumers and they are less interested in buying it. The article concludes with a discussion on the implications of this research for sustainable organisations.
\end{abstract}

\section{Keywords}

Corporate sustainability; Green product; Morality; Tainted altruism; Zero-sum heuristic

\section{Citation}

Chakravarti, J., \& Basso, F. (2020). An intentional profit-generating strategy can be detrimental to a sustainable organisation. Journal of Cleaner Production, 125057. https://doi.org/10.1016/j.jclepro.2020.125057 


\section{An intentional profit-generating strategy can be detrimental to a sustainable organisation}

\section{Introduction}

The past few decades have witnessed an increased social consciousness about the rising global threat of climate change. This increased awareness has led to greater numbers of consumers looking to switch to sustainable products, as well as a rapid growth in sustainable organisations to meet this rising demand. Organisations that prioritise sustainability seek to develop products that aim to reduce environmental damage, through the processes of design, manufacturing, packaging, recycling and so on (Dangelico and Vocalelli, 2017; Ginsberg and Bloom, 2004). One of the major challenges that sustainable organisations face is formulating the right "green-marketing" strategy for their products. The philosophy behind green marketing is quite different from traditional marketing theories. With a green marketing approach, it is important to understand not only commercial exchange relationships, but also the organisation's relationship with society (Chamorro and Bañegil, 2006) and consumer perceptions of the same. As such, sustainable organisations face some challenges pertaining to consumer attitudes and perceptions that are unique to this industry. First, they face additional public scrutiny over making misleading or exaggerated claims about the sustainability of their products, a phenomenon termed as 'greenwashing' (Delmas and Burbano, 2011). Sustainable organisations are under additional pressure to gain consumer trust and develop a marketing strategy that successfully tackles scepticism, confusion, and distrust amongst consumers (Goh and Balaji, 2016). Second, sustainable organisations can also face negative judgement if they are perceived by consumers as adopting a strategy designed to maximise profits (Makov and Newman, 2016). In this article, we suggest that manipulating intentionality in the context of profit making increases this negative judgement because it favours the adoption of a zero-sum heuristic in which superiority in terms of profitability is compensated by inferiority in terms of sustainability. More specifically, through experimental evidence, the present research shows that when consumers are presented with a profit-generating strategy that is intentional (vs. unintentional), they infer that the organisation is devoting greater resources to make profit rather than to make the product more sustainable, which leads to lower perceived eco-friendliness and lower intentions to buy. The implications of this research for green marketing strategy within sustainable organisations are discussed in conclusion.

\section{Perceptions of profit-making in sustainable organisations}

The academic debate around the rationale behind organisations seeking sustainability suggests two main perspectives. First, the profit-seeking theory, or "business case" discourse, argues that companies will adopt sustainable practices for the purpose of increasing their profits, creating financial advantages, and for economic success of the organisation (e.g., Lee, 2008; Rode et al., 2020; Schaltegger and Hörisch, 2017; Windsor, 2006). Second, the legitimacy-seeking view emphasises the importance of social and cultural norms, societal obligations, and expectations in driving sustainability decisions (Bruton et al., 2010). This theory argues that companies strive for sustainability to seek legitimacy by meeting societal obligations, rather than for profit maximisation (Lansiluoto and Jarvenpaa, 2010), which in turn shapes consumers' perceptions of pro-environmental organisations. At organisational level, consumers can form certain perceptions regarding marketing strategies based on an organisation's reputation for prioritising social responsibility or quality. For instance, research showed that consumers have more favourable responses towards low-fit brand 
extensions and are more likely to support them when an organisation has a reputation for social responsibility (Johnson et al., 2019).

People perceive pro-environmental behaviour as an act that is not motivated by self-interest but performed for the welfare of others and the environment (Asensio and Delmas, 2015). Prior literature shows that pursuing self-interest during acts that are charitable or pro-social in nature, is negatively perceived (Benkler, 2011). Self-interest and market-oriented outcomes are seen to have a corrupting influence on behaviours that are communally oriented (e.g., Bhattacharjee et al., 2017; Newman and Cain, 2014). An example of this is a study inspired by the controversy around Pallotta Teamworks, a for-profit organisation that raised money for charity, which showed that people are willing to forgo earning more money for a charity when the promoter raising money for this charity also made profit (Newman and Cain, 2014). Studies also find that there are differences in consumers' attitudes towards profit-generating aspects of social organisations as compared to for-profit enterprises (e.g., Lee et al., 2017). For instance, people perceive profit-making aspects of social enterprises as less favourable, including payment of higher salaries to employees of social organisations (Choi et al., 2020). Similarly, studies show that the acceptance of green products is reduced when they are marketed with monetary incentives (Muradian et al., 2013) and increased when associated with altruistic and pro-social incentives (Bolderdijk et al., 2013). Consumers perceive organisational "win-win" strategies that aim to increase profits while meeting environmental goals as less favourable than strategies that focus solely on profit-maximisation, without any sustainability initiatives (Makov and Newman, 2016).

The tension between market and communal relationships is presented as one of the main mechanisms explaining why organisations are negatively evaluated when proenvironmental efforts provide self-interested gains. Market and communal relationships are characterised by a different set of social norms, values and codes of conduct (Tetlock and McGraw, 2005). In market relationships, goods and services are exchanged for money and there exists a directly proportional relationship between effort and payment. On the other hand, communal relationships involve unilateral exchanges without any monetary involvement and effort is fuelled instead by pro-social or altruistic motives (Heyman and Ariely, 2004). Thus, when there is an interaction between market and communal relationships, monetary incentives can cause a decline in pro-social behaviour (Frey and Jegen, 2001; Gneezy and Rustichini, 2000; Mellström and Johannesson, 2008). Combining profit-making and pro-social motives presents a clash between what is perceived as "profane" and "sacred", which are two distinct psychological divides (Heyman and Ariely, 2004). Actions or strategies that promote both profits and pro-social objectives (such as environmental sustainability) can be perceived as breaching the fine line that exists between social relationships that are communally oriented versus those that are profit-oriented. Recent research has also highlighted a complementary explanation. Studies examining perceptions of profit-making firms show that people hold negative views regarding their effects on society (Aaker et al., 2010; Bhattacharjee et al., 2017). Indeed, it has been found that people tend to adopt a zero-sum heuristic when considering profitability. Namely, people consider that increasing profitability is achieved by sacrificing societal benefits, which nurtures anti-profit beliefs (Batthacharjee et al., 2017). For instance, organisations are seen as being more harmful to society when they are labelled "for-profit" rather than "non-profit," and increasing harm to society is considered as a strategy for increasing profitability (Batthacharjee et al., 2017). Along this line of argument, a profit-making strategy appears to be incompatible with a sustainable goal, which is supposed to benefit society. 


\section{Perceptions of intentions and resource allocation}

The way sustainable organisations communicate their intentions may however influence perceptions. Studies show that people often use intentions as strong indicators for making judgements about behaviours and social interactions. For instance, selfish intentions are equated with negative outcomes, even when this is not the case (Inbar et al., 2012). By extension, profit intentions are considered harmful to society and lead to negative judgements, even though they may be mutually beneficial to the company and to society (Bhattacharjee et al., 2017). Given that profit intentions are equated with societal harm (Bhattacharjee et al., 2017) and that intended harms are considered more blameworthy than equivalent unintended harms (Knobe, 2006), intentions can act as important heuristics in decision-making and play an influential role in shaping how people judge outcomes about economic actors.

Interestingly, manipulating intentionality also plays an essential role in consumers' evaluations of a product. For example, when organisations present themselves as intentionally making a product better for the environment, consumers have lower intentions to buy it. This is because they are more likely to consider that the organisation devoted greater resources toward sustainability and invested fewer resources in quality (Newman et al., 2014). As for anti-profit beliefs (Bhattacharjee et al., 2017), the cognitive mechanism that underlies this reasoning is based on consumer perceptions of resource allocation as zero-sum (Chernev, 2007). The zero-sum heuristic here suggests that, when a given product (e.g., a household cleaner) is presented as designed to be superior on one characteristic (e.g., sustainability), consumers tend to consider that this superiority is compensated by inferiority on another one (e.g., quality), which in turn leads to negative perceptions among consumers (Newman et al., 2014). The effect of the zero-sum heuristic on these negative perceptions can nonetheless be attenuated when consumers are given information that the organisation unintentionally (rather than intentionally) made the product better for the environment. In other words, consumers perceive sustainable products more favourably when the environmental benefits are an unintended consequence of production, rather than an intentional effort (Newman et al., 2014).

Against this background, we investigate whether marketing strategies where sustainable organisations present themselves as intentionally profit-making, influence consumer perceptions and willingness to purchase a product. When sustainable organisations indicate that a product is intentionally profit-making, consumers perceive the organisation as primarily market oriented rather than communally oriented. Information on intentionality will then lead to perceptions about resource allocation - consumers will infer that the organisation devoted greater resources to making profits rather than increasing product sustainability. This product will thus appear less sustainable and consumers will be less interested in buying it. Through a specific serial mediation model, we thus hypothesise that when a sustainable product is said to be intentionally (vs. unintentionally) profit-generating, consumers will infer that the organisation diverted more resources away from making this product better for the environment. This inference about resource allocation will lead to lower eco-friendliness ratings and lower purchase intent (i.e., intention to be market-oriented $=>$ resource allocation $\Rightarrow$ eco-friendliness $=>$ purchase intent). In line with this argument, we hypothesise that:

\section{H1a}

Consumers will infer that a sustainable organisation diverted more resources away from making a product better for the environment when it is intentionally (vs. unintentionally) profit-generating.

\section{H1b}


Consumers will infer that a sustainable product is less eco-friendly when it is intentionally (vs. unintentionally) profit-generating.

H1c

Consumers will be less likely to purchase a sustainable product when it is intentionally (vs. unintentionally) profit-generating.

\section{Perceptions of intentional versus unintentional profit-generating strategies in sustainable organisations}

Through an online experiment, we tested the effect of manipulating intentionality to generate profits, and whether this influenced purchase intent and consumer perceptions regarding resource allocation. The experiment tested our set of hypotheses through a serial mediation model. According to this model, when a sustainable organisation is intentionally profit-generating, consumers will infer that this organisation diverted resources away from making this product sustainable (H1a), which will decrease its eco-friendliness (H1b) and intentions to buy it (H1c) (i.e., intention to be market-oriented $\Rightarrow>$ resource allocation $=>$ ecofriendliness $=>$ purchase intent). We followed the procedure described by Newman et al. (2014) to manipulate intentionality to make reference to the organisation's allocation of resources.

\section{Method}

One-hundred participants were recruited from Amazon's Mechanical Turk in exchange for $\$ 0.40$ compensation. The experiment was run online (using Qualtrics) as a twocondition (profit: intended, unintended) between-subjects design. This study was approved by the ethics committee of the Department of Psychological and Behavioural Science of the London School of Economics. The following quality control techniques recommended for research on Amazon's Mechanical Turk (e.g., Friesen et al., 2014; Mason and Suri, 2012) were used for participant screening: (a) timing checks; (b) 'red herring' questionnaire item embedded in the NEP Scale; (c) specific manipulation check about intentionality, (d) a voluntary withdrawal question at the end of the study asking participants whether they answered with care and diligence, explicitly stating that there would be no penalty for answering 'no'; leaving seventy-one participants (Female $=27$; Mage $=37.58 ; S D=11.41$ ). All participants were first presented with a description of NetRetail as an environmentally sustainable organisation. They were told that NetRetail manufactures eco-friendly household products and has been developing a new formula for dishwashing soap. Participants in the 'unintended' condition learnt that: 'As an unintended consequence, this new dishwashing soap is significantly more profit-generating than competing brands', while in the other condition, profit occurred as 'initially intended' (see Appendix).

Participants then assessed the product's eco-friendliness ('How eco-friendly do you think this new dishwashing soap is?' $1=$ Not at all eco-friendly, $9=$ Very eco-friendly). They also reported their agreement with the following resource allocation statement: 'Do you think that in order to make the dishwashing soap more profit-generating, the company took resources away from making this product better for the environment?' $(1=$ Definitely not, $9=$ Definitely). Participants then indicated their intention to buy this product on a 9-point scale ('How likely are you to buy this product?' $1=$ Not at all likely, $9=$ Very likely). Last, to control for pro-environmental attitudes, at the very end of the study, participants were also asked to complete the 15-item New Ecological Paradigm (NEP) Scale and their responses on a 5-point scale $(1=$ Strongly agree, $5=$ Strongly disagree $)$ were summated according to the scoring system suggested (Dunlap et al., 2000). 


\section{Results}

Manipulation checks. Bilateral independent t-tests revealed that pro-environmental attitudes were similar amongst participants in both conditions $\left(M_{\text {Intended }}=40.21, S D=4.99\right.$;

$\left.M_{\text {Unintended }}=40.86, S D=3.95 ; t(69)=-.62, p=.54\right)$.

Resource allocation. As predicted, bilateral independent $t$-test revealed that participants thought that the green organisation had diverted more resources away from making this product better for the environment when it was intentionally $(M=5.88, S D=1.98)$ (vs. unintentionally; $M=4.51, S D=2.09)$ profit-generating $(t(69)=2.83, p=.006)$. Thus H1a was supported.

Eco-friendliness. Bilateral independent $t$-test confirmed that eco-friendliness was rated lower when the green product was intentionally $(M=5.68, S D=2.14)$ (vs. unintentionally; $M=6.73, S D=1.64)$ profit-generating $(t(69)=-2.33, p=.022)$. Thus H1b was supported. Purchase intent. Consistent with $\mathrm{H} 1 \mathrm{c}$, participants expressed lower purchase intent when the green product was intentionally $(M=5.21, S D=1.85)$ (vs. unintentionally; $M=6.27$, $S D=1.69)$ profit-generating $(t(69)=-2.52, p=.014)$.

Additional analyses. Results remained significant for every dependent variable: resource allocation $(F(1,66)=5.672, p=.020)$, eco-friendliness $(F(1,66)=4.941, p=.030)$ and intention to buy $(F(1,66)=6.755, p=.012)$, after including covariates (age, gender and NEP scores). Results are depicted in Fig. 1.

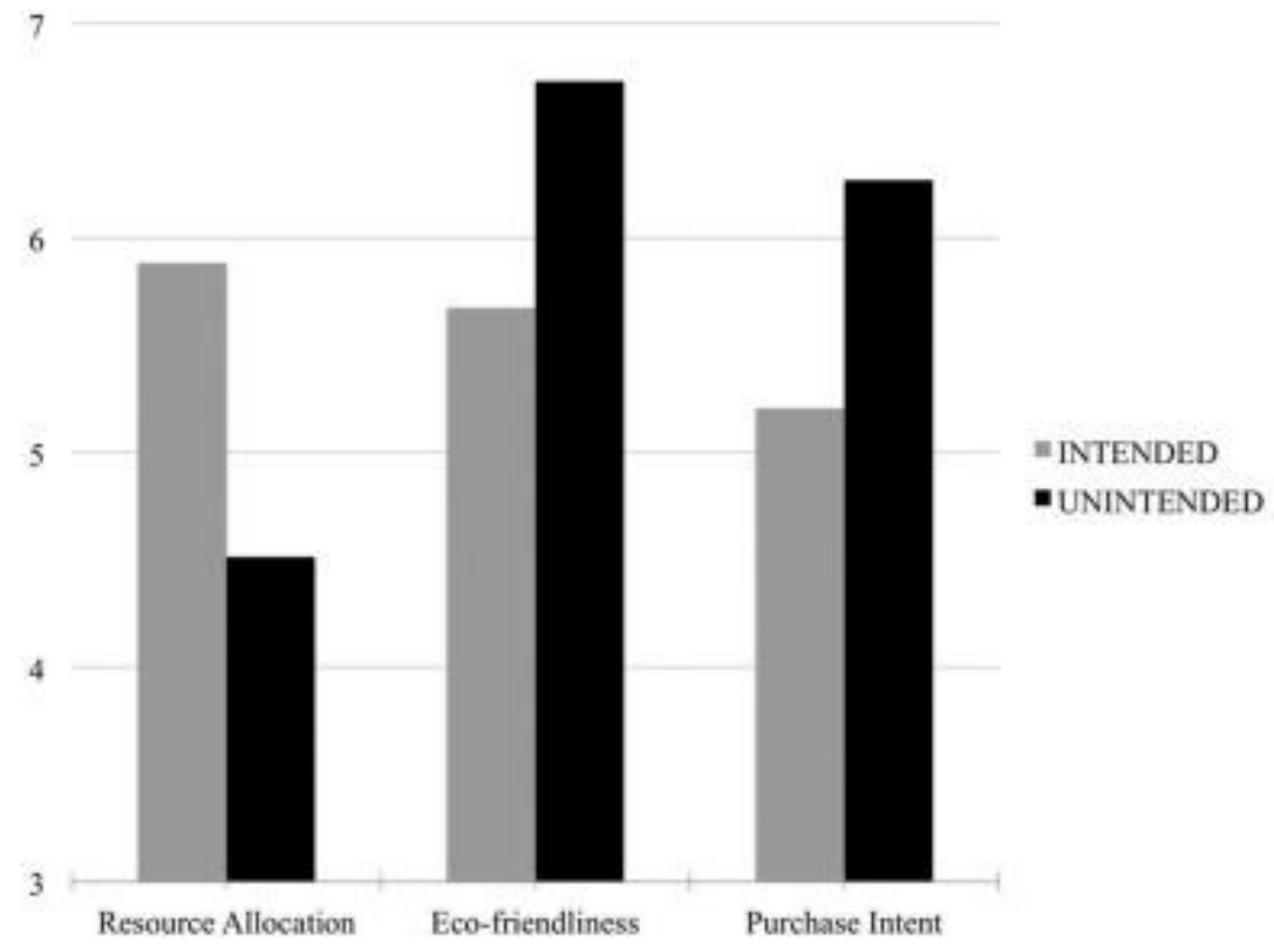

Fig. 1. Mean ratings of resource allocation, eco-friendliness and purchase intent when the when the green product was intentionally (vs. unintentionally) profit-generating.

Mediation analysis. The data was then submitted to a serial mediation analysis to test the predicted relationship between resource allocation, eco-friendliness, and purchase intent (i.e., intention to be market-oriented $=>$ resource allocation $=>$ eco-friendliness $=>$ purchase intent), using model 6 of the macro PROCESS (Hayes, 2013). We dummy coded the 
conditions as follows: $0=$ unintended, $1=$ intended, we entered eco-friendliness and resource allocation as potential mediators, and the intention to purchase the green product as dependent variable. A bootstrap analysis with 5000 samples (Preacher and Hayes, 2008) indicated that the full serial mediation model using both eco-friendliness and resource allocation was significant (indirect effect $=-.296, S E=.134,95 \% C I=-.659$ to -.097 ). Results of the serial mediation analysis remained significant (indirect effect $=-.241, S E=$ $.122,95 \% C I=-.505$ to -.033 ) after including covariates (age, gender and NEP scores). Additional analyses indicated that the 'reverse' model (i.e., intention to be market oriented $=>$ eco-friendliness $=>$ resource allocation $=>$ purchase intent) was not significant (indirect effect $=.024, S E=.080,95 \% C I=-.122$ to 0.163 ), suggesting that the predicted model best explained our data. Results from mediation analysis are depicted in Fig. 2.

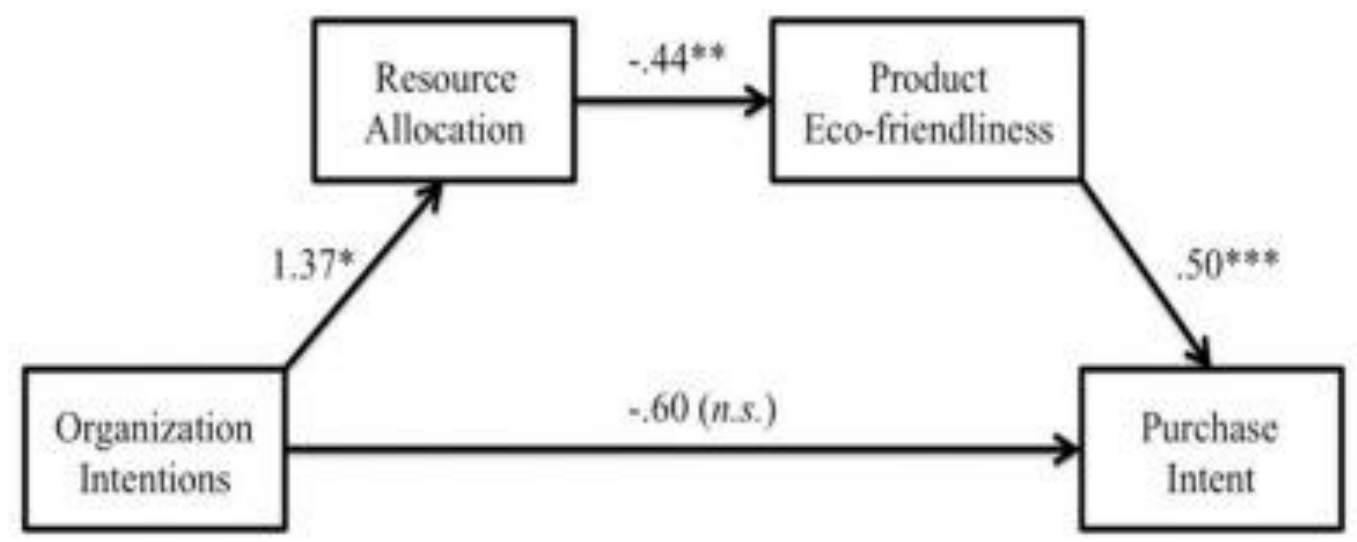

Fig. 2. Serial mediation model showing that when a green organisation is market-oriented because its green product is intentionally (vs. unintentionally) profit-generating, consumers infer that this organisation diverted more resources away from making this product better for the environment, which decreases its eco-friendliness and intentions to buy it $(* p<.01$; $* * p<.001 ; * * * p<.0001)$.

\section{Discussion}

Although companies' responsibility towards society is usually presented as the main motivator to promote sustainability, a "business case" discourse has recently been described as an alternative which portrays sustainability as a win-win strategy to increase profitability (e.g., Lee, 2008; Rode et al., 2020; Windsor, 2006). There already exists a substantial body of literature dedicated towards understanding the various types of green marketing strategies (e.g., Dangelico and Vocalelli, 2017), but little is known about consumer perceptions and the underlying reasoning behind them when it comes to the trade-off between sustainability and profitability (Makov and Newman, 2016). The present research contributes to deepening our understanding of how consumers perceive a marketing strategy promoting sustainability as source of profitability, using the literature on intentionality and the zero-sum heuristic (e.g., Bhattacharjee et al., 2017; Chernev, 2007; Newman et al., 2014). The current study findings reveal that there exists a strong bias against sustainable organisations when they are presented as being intentionally market-oriented.

More specifically, this research shows that when consumers are informed that a sustainable organisation is intentionally profit-generating, they perceive it as having diverted away resources from making the product better for the environment, considering the resource allocation within the sustainable organisation as zero-sum. Applying the zero-sum heuristic, consumers considered that a product intentionally superior in one characteristic (i.e. profit- 
maximisation) was compensated by being inferior in another characteristic (i.e. environmentally friendly). Interestingly, in the unintentional profit-generating condition, participants did not hold similar negative perceptions regarding the organisation's resource allocation, thereby suggesting that profit-generating intentions are judged more harshly even when they lead to sustainable outcomes. In both of our experimental conditions, consumers received the same information regarding the product and the fact that it was earning higher profits for the sustainable organisation than other brands, the only difference being whether this was intentional or an unintended consequence. Thus, based on intentionality, consumers made negative judgements about resource allocation, suggesting that intentionality plays an important role in consumer perceptions of resource allocation within profit-oriented sustainable organisations as zero-sum.

In addition to making judgements regarding resource allocation, consumers also perceived the product to be significantly less eco-friendly and were less likely to purchase it when it was intentionally profit-making. When the profit-generating strategy was intentional, consumers viewed the organisation as devoting less resources towards making the product sustainable, thereby perceived it to be less eco-friendly than in the unintended condition. Consumers also reported having significantly lower purchase intentions for the intentionally profit-generating product. As evidenced by the literature, we suggest that the overarching cognitive mechanism for negatively evaluating sustainable organisations that are intentionally profit-making is the strife between mixing market and communal relationships, and altruistic and profit-seeking motives (e.g., Clark and Mills, 1993; Fiske, 1992; Tetlock and McGraw, 2005). Consistent with literature, this suggests that there is a strong cognitive link in people's minds associating pro-environmental behaviour in the same mental schema as other prosocial acts such as charitable giving or blood donation (Benkler, 2011; Heyman and Ariely, 2004; Newman and Cain, 2014). Our results show that consumers prefer a sustainable organisation to not intentionally adopt a market-orientation strategy because intentions of profit-making are deemed incompatible with the idea of sustainability and such organisations are perceived as less sustainable.

Consistent with prior research, our results show that people rely on intentions for judging outcomes (e.g., Cushman, 2008; Inbar et al., 2012), and tend to equate profit intentions with negative outcomes at societal level (e.g., Bhattacharjee et al., 2017; Choi et al., 2020; Lee et al., 2017), including sustainability (Makov and Newman, 2016). By taking into account the tension between profitability and sustainability, expressing the contradiction between exchange and communal norms (e.g., Clark and Mills, 1993; Fiske, 1992; Heyman and Ariely, 2004; Tetlock and McGraw, 2005), this article demonstrates that consumers adopt a zero-sum heuristic to infer that profit-generating intentions lead to a negative evaluation of a sustainable product. In this perspective, the "win-win" strategy designed to maximise profits while minimising environmental impacts, and popularised by the "business case" discourse (e.g., Rode et al., 2020),can backfire as consumers perceive superiority on one dimension (here, profitability) as compensated by inferiority on the other one (sustainability).

From a managerial perspective, our findings shed further light on why companies have struggled to implement profitable sustainability programs in the past (Choi et al., 2020; Rode et al., 2020). Indeed, sustainable corporations looking to promote green products face consistent challenges when it comes to adopting the right marketing strategies. Consumers often report that they would prefer purchasing a green product over a less-sustainable one when "all things are equal". However, these other things are rarely equal in people's minds (e.g., Auger and Devinney 2007; Chernev and Blair, 2020; Luchs et al., 2010; Skard et al., 2020), thus setting up unique challenges for sustainable corporations (Ginsberg and Bloom, 2004). This research shows that given its negative association with sustainability, profitability is one of these unique challenges (Rode et al., 2020). However, this research also shows that 
the ways in which information is framed can shape consumer perceptions and how they consider sustainability, and therefore contributes to overcoming its negative association with profitability. Framing information can shape the way people consider sustainability (e.g., Asensio and Delmas, 2015; Bolderdijk et al., 2013; Delmas et al., 2013; Evans et al., 2013; Makov and Newman, 2016; Rode et al., 2020; van der Linden et al., 2015). In light of our results, our main recommendations for sustainable organisations are as follows. First, we suggest adding the intended/unintended effect to the communication toolbox in order to avoid the negative backlash experienced when aspects of market-orientation are promoted. Indeed, consumers are more likely to perceive a product as environmentally sustainable when it is unintentionally profit-generating. Sustainable organisations could use this effect to promote their commitment to sustainability. Second, our research supports the idea that sustainable organisations should emphasise the altruistic value of the green product rather than focusing on utilitarian aspects such as quality and profit-generation, which are not the main motivators for green consumers. These findings have thus important implications for sustainable organisations on how they can best communicate the environmental benefits of their products to consumers.

The results of this article need to be seen in light of certain limitations. First, our findings rely on self-reported data from participants, which have the potential to lead to bias (e.g., Cerri et al., 2019). For instance, participants are asked to self-report on whether information about intention to generate profit led to perceptions about resource allocation, rather than measure this association implicitly (e.g., Bhattacharjee et al., 2017). Second, although the findings remain similar after controlling for participants' age, gender and proenvironmental attitudes, it is possible that other factors such as income and educational background might influence their perceptions (e.g., Song et al., 2020).

Our findings also prompt important questions for further research undertakings. First, it would be interesting to observe whether these negative perceptions towards profit-generating strategies among sustainable organisations hold true across different segments of green consumers and in different cultural contexts (e.g., Ceglia et al., 2015; Chwialkowska et al., 2020; González-Rodríguez et al., 2019). Second, our research utilises "sustainable organisations" in a broad sense. It would be interesting to explore whether consumer perceptions towards profit-generating strategies vary to certain degrees between sustainable products that are generally attributed to different levels of pro-social behaviour (e.g., Engert et al., 2016; McWilliams et al., 2006). For example, consumers might perceive it to be more acceptable to adopt a profit-generating strategy with green automobiles rather than with a product that reduces plastic that would otherwise damage marine wildlife. We see these as important avenues for further research in this area.

\section{Conclusion}

The present research contributes to the literature on how consumer perceptions play an important role in the success of green-marketing strategies (Chamorro and Bañegil, 2006; Dangelico and Vocalelli, 2017). To our knowledge, this research presents one of the first investigations of consumer perceptions towards the effects of intentionality of profit-making behaviour within sustainable organisations (Makov and Newman, 2016). These results are informative to sustainable organisations seeking to market their products in terms of developing effective marketing strategies, and have important implications for sustainable organisations in terms of how they promote themselves and market their products to consumers. This research finds a strong bias against sustainable organisations when they promote themselves as being intentionally profit-generating. In other words, intentions of profit-making being deemed incompatible with the idea of sustainability, such organisations 
are perceived as less sustainable. This research also shows that when sustainable organisations suggest that their product is intentionally profit-generating, consumers respond negatively and are less likely to purchase this green product. They are also more likely to infer that the company invested fewer resources in eco-friendliness. In other words, consumers adopt a zero-sum heuristic (Bhattacharjee et al., 2017) and tend to think that, when a sustainable organisation is superior on the profitability dimension, it is compensated by an inferiority on the sustainability dimension. Consumer perceptions regarding the intention behind sustainable organisations pursuing a strategy that promotes marketorientation, can thus play an important role in the evaluation of sustainable products (Newman et al., 2014). As sustainable organisations can be negatively perceived when their products are intentionally profit-making, it is suggested that profits should be presented as unintended consequences of production to be judged less harshly.

\section{Financial disclosure}

The authors declare that no competing interests exist.

\section{Funding}

This study was funded by the London School of Economics and Political Science (Department of Psychological and Behavioural Science).

\section{CRediT authorship contribution statement}

Jayani Chakravarti: Conceptualization, Writing - original draft, Writing - review \& editing. Frédéric Basso: Conceptualization, Methodology, Formal analysis, Investigation, Resources, Writing - original draft, Writing - review \& editing, Visualization, Supervision, Project administration, Funding acquisition.

\section{Declaration of competing interest}

The authors declare that they have no known competing financial interests or personal relationships that could have appeared to influence the work reported in this paper. 


\section{Appendix A. Experimental stimuli}

\section{Intended condition}

NetRetail is an environmentally sustainable organization that manufactures a range of ecofriendly household products. One of NetRetail's biggest sectors is household cleaning products such as detergents and cleaning sprays. In a meeting with the CEO of NetRetail, the Vice President of R\&D, Joe Smith, announces that the R\&D team has been working for months on developing a new formula for dishwashing soap.

Joe Smith states, 'As we initially intended, this new dishwashing soap is significantly more profit-generating than competing brands.' Results analyzed by independent agencies confirm that the new dish soap is indeed making more money for NetRetail than any other brand in the marketplace.

\section{Unintended condition}

NetRetail is an environmentally sustainable organization that manufactures a range of ecofriendly household products. One of NetRetail's biggest sectors is household cleaning products such as detergents and cleaning sprays. In a meeting with the CEO of NetRetail, the Vice President of R\&D, Joe Smith, announces that the R\&D team has been working for months on developing a new formula for dishwashing soap.

Joe Smith states, 'As an unintended consequence, this new dishwashing soap is significantly more profit-generating than competing brands.' Results analyzed by independent agencies confirm that the new dish soap is indeed making more money for NetRetail than any other brand in the marketplace. 


\section{References}

J. Aaker, K.D. Vohs, C. Mogilner Nonprofits are seen as warm and for-profits as competent: firm stereotypes matter J. Consum. Res., 37 (2010), pp. 224-237

O.I. Asensio, M.A. Delmas Nonprice incentives and energy conservation Proc. Natl. Acad. Sci. Unit. States Am., 112 (6) (2015), pp. E510-E515

P. Auger, T.M. Devinney Do what consumers say matter? The misalignment of preferences with unconstrained ethical intentions J. Bus. Ethics, 76 (4) (2007), pp. 361-383

Y. Benkler The unselfish gene Harv. Bus. Rev., 89 (7/8) (2011), pp. 76-85

A. Bhattacharjee, J. Dana, J. Baron Anti-profit beliefs: how people neglect the societal benefits of profit J. Pers. Soc. Psychol., 113 (5) (2017), p. 671

J.W. Bolderdijk, L. Steg, E.S. Geller, P.K. Lehman, T. Postmes Comparing the effectiveness of monetary versus moral motives in environmental campaigning Nat. Clim. Change, 3 (4) (2013), pp. 413-416

G.D. Bruton, D. Ahlstrom, H.L. Li Institutional theory and entrepreneurship: where are we now and where do we need to move in the future? Enterpren. Theor. Pract., 34 (3) (2010), pp. $421-440$

D. Ceglia, S.H. de Oliveira Lima, Á.L. Leocádio An alternative theoretical discussion on cross-cultural sustainable consumption Sustain. Dev., 23 (6) (2015), pp. 414-424

J. Cerri, J. Thøgersen, F. Testa Social desirability and sustainable food research: a systematic literature review Food Qual. Prefer., 71 (2019), pp. 136-140

A. Chamorro, T.M. Bañegil Green marketing philosophy: a study of Spanish firms with ecolabels Corp. Soc. Responsib. Environ. Manag., 13 (1) (2006), pp. 11-24

A. Chernev Jack of all trades or master of one? Product differentiation and compensatory reasoning in consumer choice J. Consum. Res., 33 (4) (2007), pp. 430-444

A. Chernev, S. Blair When sustainability is not a liability: the halo effect of marketplace morality J. Consum. Psychol. (2020), 10.1002/jcpy.1195

E. Choi, E. Kim, I. Kim, I. Choi Attitude toward social enterprises: a comparison between for-profit and social enterprise employees Sustainability, 12 (7) (2020), p. 2720

A. Chwialkowska, W.A. Bhatti, M. Glowik The influence of cultural values on proenvironmental behavior J. Clean. Prod. (2020), p. 122305

M.S. Clark, J. Mils The difference between communal and exchange relationships: what it is and is not Pers. Soc. Psychol. Bull., 19 (6) (1993), pp. 684-691

F. Cushman Crime and punishment: Distinguishing the roles of causal and intentional analyses in moral judgment Cognition, 108 (2) (2008), pp. 353-380 
R.M. Dangelico, D. Vocalelli “Green Marketing": an analysis of definitions, strategy steps, and tools through a systematic review of the literature J. Clean. Prod., 165 (2017), pp. 12631279

M.A. Delmas, V.C. Burbano The drivers of greenwashing Calif. Manag. Rev., 54 (1) (2011), pp. 64-87

R.E. Dunlap, K.D. Van Liere, A.G. Mertig, R.E. Jones New trends in measuring environmental attitudes: measuring endorsement of the New Ecological Paradigm: a revised NEP scale J. Soc. Issues, 56 (3) (2000), pp. 425-442

S. Engert, R. Rauter, R.J. Baumgartner Exploring the integration of corporate sustainability into strategic management: a literature review J. Clean. Prod., 112 (2016), pp. 2833-2850

L. Evans, G.R. Maio, A. Corner, C.J. Hodgetts, S. Ahmed, U. Hahn Self-interest and proenvironmental behaviour Nat. Clim. Change, 3 (2) (2013), pp. 122-125

A.P. Fiske The four elementary forms of sociality: framework for a unified theory of social relations Psychol. Rev., 99 (4) (1992), pp. 689-723

B.S. Frey, R. Jegen Motivation crowding theory J. Econ. Surv., 15 (5) (2001), pp. 589-611

J.P. Friesen, A.C. Kay, R.P. Eibach, A.D. Galinsky Seeking structure in social organization: compensatory control and the psychological advantages of hierarchy J. Pers. Soc. Psychol., 106 (4) (2014), pp. 590-608

J.M. Ginsberg, P.N. Bloom Choosing the right green marketing strategy

MIT Sloan Manag. Rev., 46 (1) (2004), pp. 79-84

U. Gneezy, A. Rustichini A fine is a price J. Leg. Stud., 29 (1) (2000), pp. 1-17

S.K. Goh, M.S. Balaji Linking green skepticism to green purchase behavior J. Clean. Prod., 131 (2016), pp. 629-638

M.R. González-Rodríguez, M.C. Díaz-Fernández, S. Biagio The perception of socially and environmentally responsible practices based on values and cultural environment from a customer perspective J. Clean. Prod., 216 (2019), pp. 88-98

J. Heyman, D. Ariely Effort for payment: a tale of two markets Psychol. Sci., 15 (11) (2004), pp. 787-793

Y. Inbar, D.A. Pizarro, F. Cushman Benefiting from misfortune: when harmless actions are judged to be morally blameworthy Pers. Soc. Psychol. Bull., 38 (2012), pp. 52-62

Z.S. Johnson, H. Mao, S. Lefebvre, J. Ganesh Good guys can finish first: how brand reputation affects extension evaluations J. Consum. Psychol., 29 (4) (2019), pp. 565-583

J. KnobeThe concept of intentional action: a case study in the uses of folk psychology Phil. Stud., 130 (2) (2006), pp. 203-231 
A. Länsiluoto, M. JärvenpääGreening the balanced scorecard Bus. Horiz., 53 (4) (2010), pp. 385-395

M.D.P. Lee A review of the theories of corporate social responsibility: its evolutionary path and the road ahead Int. J. Manag. Rev., 10 (1) (2008), pp. 53-73

S. Lee, L.E. Bolton, K.P. Winterich To profit or not to profit? The role of greed perceptions in consumer support for social ventures J. Consum. Res., 44 (4) (2017), pp. 853-876

M.G. Luchs, R.W. Naylor, J.R. Irwin, R. Raghunathan The sustainability liability: potential negative effects of ethicality on product preference J. Market., 74 (5) (2010), pp. 18-31

A. McWilliams, D.S. Siegel, P.M. Wright Corporate social responsibility: strategic implications J. Manag. Stud., 43 (1) (2006), pp. 1-18

T. Makov, G.E. Newman Economic gains stimulate negative evaluations of corporate sustainability initiatives Nat. Clim. Change, 6 (9) (2016), pp. 844-846

W. Mason, S. Suri Conducting behavioral research on Amazon's Mechanical Turk Behav. Res. Methods, 44 (1) (2012), pp. 1-23

C. Mellström, M. Johannesson Crowding out in blood donation: was Titmuss right? J. Eur. Econ. Assoc., 6 (4) (2008), pp. 845-863

R. Muradian, M. Arsel, L. Pellegrini, F. Adaman, B. Aguilar, B. Agarwal, et al. Payments for ecosystem services and the fatal attraction of win-win solutions: PES \& fatal attraction of win-win solutions Conservation Letters, 6 (4) (2013), pp. 274-279

G.E. Newman, D.M. Cain Tainted altruism: when doing some good is evaluated as worse than doing no good at all Psychol. Sci., 25 (3) (2014), pp. 648-655

G.E. Newman, M. Gorlin, R. Dhar When going green backfires: how firm intentions shape the evaluation of socially beneficial product enhancements J. Consum. Res., 41 (3) (2014), pp. 823-839

J. Rode, N. Heinz, M. Le Menestrel, G. Cornelissen How to encourage business professionals to adopt sustainable practices? Experimental evidence that the 'business case'discourse can backfire J. Clean. Prod. (2020), Article 124618

S. Schaltegger, J. Hörisch In search of the dominant rationale in sustainability management: legitimacy-or profit-seeking? J. Bus. Ethics, 145 (2) (2017), pp. 259-276

S. Skard, S. Jørgensen, L.J.T. Pedersen When is sustainability a liability, and when is it an asset? Quality inferences for core and peripheral attributes J. Bus. Ethics (2020), pp. 1-24, $\underline{10.1007 / \mathrm{s} 10551-019-04415-1}$

H. Song, N.A. Lewis Jr., M.T. Ballew, M. Bravo, J. Davydova, H.O. Gao, et al. What counts as an "environmental" issue? Differences in issue conceptualization by race, ethnicity, and socioeconomic status J. Environ. Psychol. (2020), Article 101404 
P.E. Tetlock, A.P. McGraw Theoretically framing relational framing J. Consum. Psychol., 15 (1) (2005), pp. 35-37

D. Windsor Corporate social responsibility: three key approaches J. Manag. Stud., 43 (1) (2006), pp. 93-114 